\title{
Variation of structural and magnetic properties with composition in the $\left(\mathrm{Co}_{x} \mathrm{Ni}_{1-x}\right)_{1.5}\left[\mathrm{Fe}(\mathrm{CN})_{6}\right] \cdot z \mathrm{H}_{2} \mathrm{O}$ series
}

\author{
Amit Kumar and S. M. Yusuf* \\ Solid State Physics Division, Bhabha Atomic Research Centre, Mumbai 400085, India \\ L. Keller \\ Laboratory for Neutron Scattering, ETHZ \& PSI, CH-5232 Villigen PSI, Switzerland
}

J. V. Yakhmi

Technical Physics \& Prototype Engineering Division, Bhabha Atomic Research Centre, Mumbai 400085, India

J. K. Srivastava and P. L. Paulose

Tata Institute of Fundamental Research, Homi Bhabha Road, Colaba, Mumbai 400005, India

(Received 28 November 2006; revised manuscript received 3 February 2007; published 15 June 2007)

\begin{abstract}
Structural and magnetic properties of the compounds $\left(\mathrm{Co}_{x} \mathrm{Ni}_{1-x}\right)_{1.5}\left[\mathrm{Fe}(\mathrm{CN})_{6}\right] \cdot z \mathrm{H}_{2} \mathrm{O}(0 \leqslant x \leqslant 1)$ have been studied by x-ray and neutron-diffraction, dc magnetization, infrared (IR), and Mössbauer spectroscopic techniques. All studied compounds of the series crystallize in the fcc structure with Fm $3 m$ space group. Detailed structural studies by x-ray diffraction followed by Mössbauer and IR studies reveal disordered structures with the presence of $\mathrm{Co} / \mathrm{Ni}-\mathrm{N} \equiv \mathrm{C}-\mathrm{Fe}-\mathrm{C} \equiv \mathrm{N}-\mathrm{Co} / \mathrm{Ni}-$ and $\mathrm{Co} / \mathrm{Ni}-\mathrm{C} \equiv \mathrm{N}-\mathrm{Fe}-\mathrm{N} \equiv \mathrm{C}-\mathrm{Co} / \mathrm{Ni}$-type linear chains along the edges of the unit-cell cube. Neutron-diffraction patterns of all the members of the series have diffuse scattering and a broad peaklike feature at the (100) position which is forbidden under the $F m 3 m$ space group. The reverse Monte Carlo simulations of this diffuse scattering, present due to structural disorders, indicate a correlated substitution of water molecules at the empty $\mathrm{Fe}(\mathrm{CN})_{6}$ sites. The magnetic ordering temperature decreases with increasing amount of the Co substitution and it is minimum for the $x=0.75$ compound. Fielddependent magnetization measurements at $1.5 \mathrm{~K}$ and up to a maximum field of $70 \mathrm{kOe}$ reveal that all compounds (except $x=1$ ) of the series are ferromagnetic with positive exchange interactions between the nearestneighbor low-spin $\mathrm{Co}^{2+}\left(S=\frac{1}{2}\right) / \mathrm{Ni}^{2+}(S=1)$ and the mixed-spin $\mathrm{Fe}^{3+}$ [low-spin $\left(S=\frac{1}{2}\right)$ and high-spin $\left.\left(S=\frac{5}{2}\right)\right]$ ions. However, the end compound $\mathrm{Co}_{1.5}\left[\mathrm{Fe}(\mathrm{CN})_{6}\right] \cdot z \mathrm{H}_{2} \mathrm{O}(x=1)$ of the series is a ferrimagnet with negative exchange interactions between the high-spin $\mathrm{Co}^{2+}\left(S=\frac{3}{2}\right)$ and the low-spin $\mathrm{Fe}^{3+}\left(S=\frac{1}{2}\right)$ and also between the low-spin $\mathrm{Co}^{2+}\left(S=\frac{1}{2}\right)$ and the high-spin $\mathrm{Fe}^{3+}\left(S=\frac{5}{2}\right)$ ions. The observed dip in the values of the lattice parameter, transition temperature, saturation magnetization, coercive field, and remanence around $x=0.75$ is ascribed due to the presence of the largest amount of structural disorder around that composition. Neutron-diffraction patterns of the compounds, down to $1.5 \mathrm{~K}$, do show negligibly small magnetic contribution to the fundamental (nuclear) Bragg reflections, however, these contributions are more than one order of magnitude smaller than the modulated diffuse scattering contributions. The effects of structural disorder, due to the presence of vacancies of the $\mathrm{Fe}(\mathrm{CN})_{6}$ and uncoordinated water molecules, and the quenched disorder, due to random substitution of $\mathrm{Ni}$ by $\mathrm{Co}$ at the $(0,0,0)$ site, on the magnetic ordering in these molecular magnetic compounds have been brought out.
\end{abstract}

DOI: $10.1103 /$ PhysRevB.75.224419

PACS number(s): 75.50.Xx, 61.12.Ld, 75.25.+z, 75.30.Cr

\section{INTRODUCTION}

Rational design of magnetic properties has always been a great challenge. The design of a desired magnetic property requires the prior knowledge of various factors like chemical composition, temperature, magnetic field, etc., affecting magnetic properties ${ }^{1-4}$ of the magnetic material. In recent years, a lot of efforts have been put to design magnetic materials with multifunctional properties. Prussian blue analogs (PBAs), ${ }^{1-18}$ represented by the general formula $A_{m}\left[B(\mathrm{CN})_{6}\right]_{n} \cdot z \mathrm{H}_{2} \mathrm{O}$ (Fig. 1) where $A$ and $B$ are transitionmetal ions, have shown very promising results in this direction. For example, the phenomena like mixed ferroferrimagnetism ${ }^{1}$ in $\left(\mathrm{Ni}_{0.22} \mathrm{Mn}_{0.60} \mathrm{Fe}_{0.18}\right)_{1.5}\left[\mathrm{Cr}(\mathrm{CN})_{6}\right]$ $\left..7 .6 \mathrm{H}_{2} \mathrm{O}\right)$, pressure tuning of magnetism and linkage isomerism $^{2}$ in $\mathrm{K}_{0.4} \mathrm{Fe}_{4}\left[\mathrm{Cr}(\mathrm{CN})_{6}\right]_{2.8} \cdot 16 \mathrm{H}_{2} \mathrm{O}$, electric- field induced conductance switching ${ }^{4}$ in $\mathrm{Rb}_{0.5} \mathrm{Co}^{\mathrm{III}} \mathrm{Co}^{\mathrm{II}}{ }_{0.25}\left[\mathrm{Fe}^{\mathrm{II}}(\mathrm{CN})_{6}\right] \cdot 5.9 \mathrm{H}_{2} \mathrm{O}$, humidity induced magnetization ${ }^{9}$ in $\left(\mathrm{Co}_{x} \mathrm{Mn}_{1-x}\right)\left[\mathrm{Cr}(\mathrm{CN})_{6}\right]_{2 / 3} \cdot z \mathrm{H}_{2} \mathrm{O}$, photoinduced magnetization ${ }^{17}$ in $\mathrm{K}_{0.2} \mathrm{Co}_{1.4}\left[\mathrm{Fe}(\mathrm{CN})_{6}\right] \cdot 9 \mathrm{H}_{2} \mathrm{O}$, electrochemical tuning of magnetic properties ${ }^{18}$ in $\mathrm{K}_{0.4} \mathrm{Co}_{1.3}\left[\mathrm{Fe}(\mathrm{CN})_{6}\right] \cdot 5 \mathrm{H}_{2} \mathrm{O}$, etc., have been observed. Therefore the systematic studies are required to explore and tune the detailed structural and magnetic properties of these important materials. In this paper, we have tried to control the magnetic properties, e.g., magnetic ordering temperature $\left(T_{C}\right)$, saturation magnetization $\left(M_{\text {sat }}\right)$, coercive field $\left(H_{C}\right)$ etc., in the PBA series, $\left(\mathrm{Co}_{x} \mathrm{Ni}_{1-x}\right)_{1.5}\left[\mathrm{Fe}(\mathrm{CN})_{6}\right] \cdot z_{2} \mathrm{H}_{2} \mathrm{O}(0$ $\leqslant x \leqslant 1$ ) by varying the Co composition $(x)$. We have described the effects of different spins (magnetic ions) on the magnetic properties of the compounds of the above series. The parent compound, $\mathrm{Ni}_{1.5}\left[\mathrm{Fe}(\mathrm{CN})_{6}\right] \cdot z \mathrm{H}_{2} \mathrm{O}$ of the series, is 


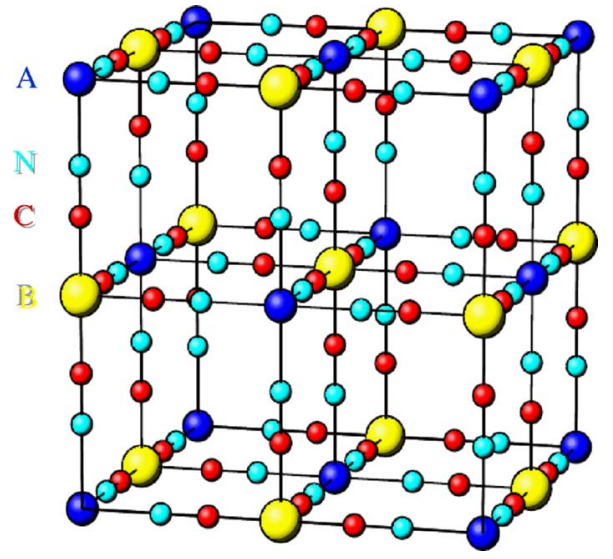

FIG. 1. (Color online) Structure of Prussian Blue analogs, $A\left[B(\mathrm{CN})_{6}\right] \cdot z \mathrm{H}_{2} \mathrm{O}$. For clarity, $\mathrm{H}$ and $\mathrm{O}$ atoms are not shown.

a ferromagnetic compound with a $T_{C}$ of $23.6 \mathrm{~K} .{ }^{19}$ On the other hand, there are contradicting reports on the magnetic ordering in the pure Co based end compound, $\mathrm{Co}_{1.5}\left[\mathrm{Fe}(\mathrm{CN})_{6}\right] \cdot z \mathrm{H}_{2} \mathrm{O}$. Juszczyk et al. ${ }^{19}$ have reported a ferromagnetic ordering between the low-spin $\mathrm{Co}^{2+}\left(S=\frac{1}{2}\right)$ and the low-spin $\mathrm{Fe}^{3+} \quad\left(S=\frac{1}{2}\right) \quad$ ionic moments for $\mathrm{Co}_{1.5}\left[\mathrm{Fe}(\mathrm{CN})_{6}\right] \cdot z \mathrm{H}_{2} \mathrm{O}$ compound whereas other groups ${ }^{17,20}$ have reported ferrimagnetic ordering between the high-spin $\mathrm{Co}^{2+}\left(S=\frac{3}{2}\right)$ and the low-spin $\mathrm{Fe}^{3+}\left(S=\frac{1}{2}\right)$ ionic moments. In this paper, we have discussed the possible origin of different spin interactions (ferrimagnetic or ferromagnetic) of the Co ions in these compounds and it is shown that the pure Co based compound is ferrimagnetic whereas the other compositions with $\mathrm{Ni}$ are ferromagnetic.

In an earlier report, we presented preliminary results on the structural and magnetic properties of $\mathrm{Co}_{0.75} \mathrm{Ni}_{0.75}\left[\mathrm{Fe}(\mathrm{CN})_{6}\right] \cdot z \mathrm{H}_{2} \mathrm{O},{ }^{12}$ the $x=0.5$ composition of the present series. In that report, we showed the presence of two crystallographic sites for the $\mathrm{Co}, \mathrm{Ni}$, and $\mathrm{Fe}$ ions using x-raydiffraction, infrared (IR), and Mössbauer spectroscopic techniques. Furthermore, dc magnetization study indicated a lowspin state for the $\mathrm{Co}^{2+}$ ions $\left(S=\frac{1}{2}\right)$ in this compound. Neutron-diffraction study on another composition, ${ }^{21}$ $\mathrm{Co}_{0.375} \mathrm{Ni}_{1.125}\left[\mathrm{Fe}(\mathrm{CN})_{6}\right] \cdot z \mathrm{H}_{2} \mathrm{O}(x=0.25)$ indicated the presence of a diffuse scattering and a non-face-centered reflection at the (100) Bragg position in the neutron-diffraction patterns. All the above facts indicate the presence of structural defects in these compounds. These structural defects play an important role in tuning their magnetic properties and arise during the sample preparation itself due to the offstoichiometry of these compounds. ${ }^{11-13,22,23}$ Particularly, the presence of the $\mathrm{Fe}(\mathrm{CN})_{6}$ vacancies and the partial occupancies of the crystalline water sites contribute to the structural defects. One additional defect (the quenched disorder) comes from the random occupation of the same $(0,0,0)$ site by the $\mathrm{Co}$ and $\mathrm{Ni}$ ions. It will therefore be very important and interesting to study the effects of structural defects on the magnetic ordering in these compounds. Here, we would like to mention that the structural defects vary with the composition $(x)$ and it is therefore very much essential to carry out a systematic investigation by studying several compositions of the present series. Such a study is essential to understand the detailed nature of the defects and their effects on the magnetic ordering across the series. These results will also be very useful in the rational design of various magnetic properties of these multifunctional materials. Thus, in the present study, we have extended our studies on the $x=0,0.25,0.5$, $0.7,0.75,0.8,0.87$, and 1 compositions of the series using $\mathrm{x}$-ray and neutron-diffraction, dc magnetization, IR, and Mössbauer spectroscopic techniques. We have discussed the effects of structural disorder on the lattice parameter $(a), T_{C}$, $M_{\text {sat }}, H_{C}$, remanence $\left(M_{R}\right)$, etc., as a function of composition $(x)$. Our studies have shown that the most disordered structure is around the $x=0.75$ composition and the prominent effects are reflected in the values of the above parameters at that composition. The results of our studies also highlight the effects of structural disorders on the spin states of the Co ions in these compounds as its spin state changes from the high spin $\left(S=\frac{3}{2}\right)$ in the end compound $(x=1)$ to the low spin $\left(S=\frac{1}{2}\right)$ in other compositions with $\mathrm{Ni}$ ions.

\section{EXPERIMENT}

The polycrystalline samples of the series were prepared by the co-precipitation method. In a typical synthesis of a composition, appropriate amounts of $0.1-\mathrm{M}$ aqueous solutions of $\mathrm{Co}\left(\mathrm{NO}_{3}\right)_{2}$ and $\mathrm{Ni}\left(\mathrm{NO}_{3}\right)_{2}$ were prepared separately. The above prepared solutions were mixed together and poured in the rapidly stirred aqueous solution of $0.1-\mathrm{M}$ $\mathrm{K}_{3} \mathrm{Fe}(\mathrm{CN})_{6}$. This resulted in the precipitate of the desired composition of the series. An excess of $\mathrm{Co} / \mathrm{Ni}$ ions $\left(\mathrm{Co}^{2+} / \mathrm{Ni}^{2+}\right.$ to $\left[\mathrm{Fe}(\mathrm{CN})_{6}\right]^{3-}$ ratio=2:1) was taken during the precipitation in order to make sure potassium free precipitates. ${ }^{24}$ The color of the precipitates changes from a pale yellow to a dark brown as we move from $\mathrm{Ni}_{1.5}\left[\mathrm{Fe}(\mathrm{CN})_{6}\right] \cdot z \mathrm{H}_{2} \mathrm{O}$ to $\mathrm{Co}_{1.5}\left[\mathrm{Fe}(\mathrm{CN})_{6}\right] \cdot z \mathrm{H}_{2} \mathrm{O}$ in the series. The resulting precipitates were filtered, washed many times with double distilled water, and finally dried under an IR lamp for $30 \mathrm{~min}$. Neutron-diffraction patterns $(\lambda=1.249 \AA)$ at room temperature were recorded at the Dhruva reactor, Trombay, India. Low temperature $(50$ and $1.5 \mathrm{~K})$ neutrondiffraction patterns for few compounds in the series were recorded at the DMC cold powder diffractometer $(\lambda$ $=2.568 \AA$ ) , SINQ, Paul Scherrer Institute, Switzerland. The $\mathrm{x}$-ray-diffraction patterns were recorded at room temperature in the $2 \theta$ range $10-75^{\circ}$ using a $\mathrm{Cu}-K_{\alpha}$ radiation. Roomtemperature Mössbauer spectra were recorded using a constant acceleration drive unit coupled with a multichannel analyzer operated in time mode. The IR spectra were recorded by incorporating the samples in a $\mathrm{KBr}$ pellet on the Bomen MB-102 Fourier transform infrared (FTIR) spectrometer. dc magnetization measurements were carried out using a commercial (Oxford Instruments) vibrating sample magnetometer as a function of temperature down to $1.5 \mathrm{~K}$ and magnetic field up to $70 \mathrm{kOe}$. In the zero-field-cooled (ZFC) measurements, the samples were cooled in the absence of a magnetic field down to the lowest temperature and the measurements were taken in the warming cycle under an applied magnetic field. The corresponding field-cooled (FC) 


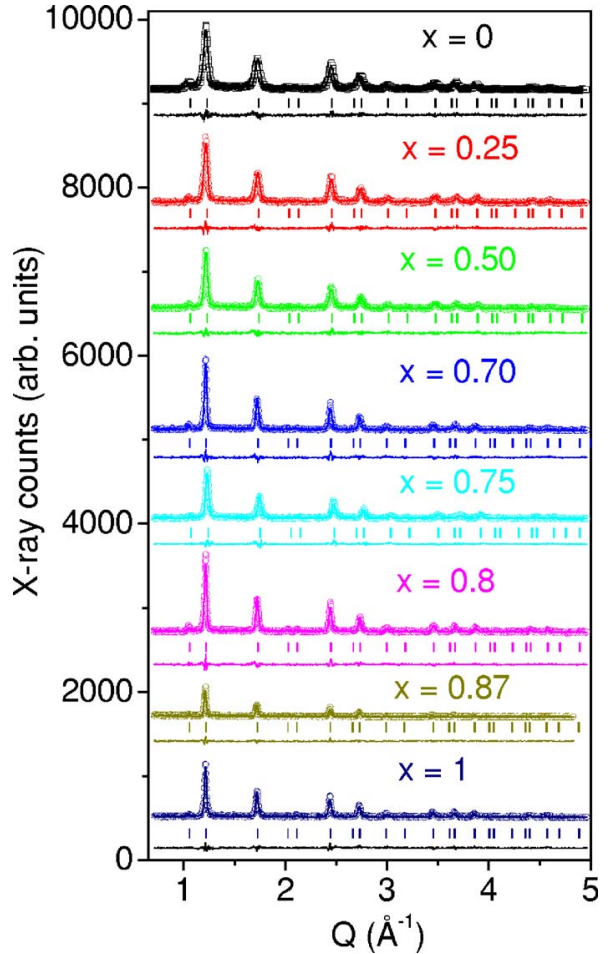

FIG. 2. (Color online) Rietveld refined x-ray-diffraction patterns for the $x=0,0.25,0.50,0.70,0.75,0.80,0.87$, and 1 compositions. The patterns are shifted relative to the $x=1$ pattern for easy viewing. Open circles show observed data, the line is the calculated pattern, and the difference between the observed and the calculated patterns is shown at the bottom of each curve. Bragg peak markers are shown as short vertical lines for each pattern.

measurements were performed by cooling the samples in the presence of magnetic fields (the same as in the ZFC case) and then carrying out the measurements in the warming cycles with field on.

\section{RESULTS AND DISCUSSION}

\section{A. X-ray-diffraction studies}

Figure 2 shows the x-ray-diffraction patterns for the $x$ $=0,0.25,0.5,0.7,0.75,0.8,0.87$, and 1 compounds of the series at room temperature. For a comparison purpose, all the diffraction data are plotted as a function of magnitude of the scattering vector $Q[=(4 \pi \sin \theta) / \lambda$, where $\theta$ is the Bragg angle]. The Rietveld refinement ${ }^{25}$ of the $x$-ray-diffraction patterns confirms the single phase for all the compounds of the series. The refinement also confirms the fcc structure with the $F m 3 m$ space group as found for most of the compounds of the PBA family. The Co and $\mathrm{Ni}$ ions occupy the $4 a$ $(0,0,0)$ and the Fe ions occupy the $4 b\left(\frac{1}{2}, \frac{1}{2}, \frac{1}{2}\right)$ crystallographic sites. The $\mathrm{C}$ and $\mathrm{N}$ atoms occupy the $24 e(x, 0,0)$ crystallographic site and connect the $\mathrm{Co} / \mathrm{Ni}$ and $\mathrm{Fe}$ ions along the edges of the unit-cell cube. Owing to the $2 / 3$ $(n: m)$ stoichiometry, $1 / 3$ of the $\mathrm{Fe}, \mathrm{C}$, and $\mathrm{N}$ sites are empty and the $\mathrm{O}$ atoms of the coordinated water molecules occupy the empty $\mathrm{N}$ sites. Therefore the $\mathrm{Fe}$ ions are surrounded by six $\mathrm{C}$ atoms in an octahedral environment and usually pos-

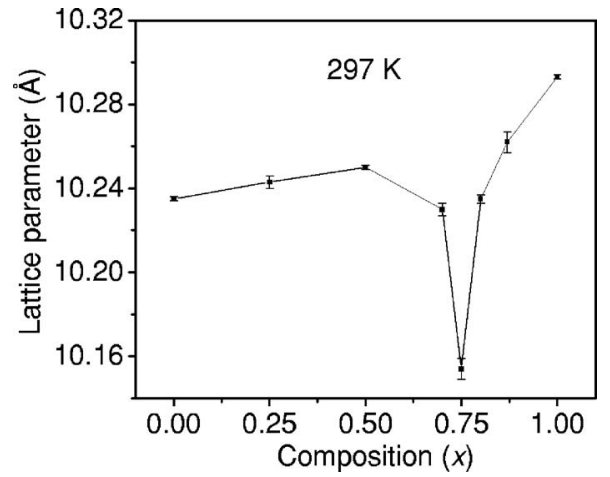

FIG. 3. Variation of lattice parameters with the composition $(x)$

sess a low-spin state due to a strong ligand field of the $\mathrm{C}$ ions. On the other hand, the $\mathrm{Co} / \mathrm{Ni}$ ions are surrounded by four $\mathrm{N}$ and two $\mathrm{O}$ atoms in an octahedral environment and may possess either a low or a high spin because of the mixed ligand field of $\mathrm{N}$ and $\mathrm{O}$. The water content was derived from the number of $\mathrm{O}$ atoms present in the unit cell. The water content for the compounds of the series (as derived from the refinement) varies from 6.3 to 6.8 per formula unit. Approximately three water molecules are present at the empty nitrogen $24 e(x, 0,0)$ site. The remaining water molecules are distributed at the interstitial $8 c\left(\frac{1}{4}, \frac{1}{4}, \frac{1}{4}\right)$ and $32 f(x, x, x)$ sites. The variation of lattice parameter with the composition $(x)$ is shown in the Fig. 3. The lattice parameter does not vary linearly with the Co doping but has a dip at the $x=0.75$ composition.

\section{B. Mössbauer spectra studies}

In order to study the spin states of the Fe ions in these compounds, Mössbauer spectra (shown in Fig. 4) at room temperature were recorded. The observed spectra are fitted with two or three components using the least-square minimization method. The values of the center shift (CS), quadrupole splitting (QS), linewidth (WDT), and relative intensities (INT) for various fitted components are given in Table I. The values of the CS obtained from the least-square-fitted data reveal that the $\mathrm{Fe}$ ions are in two (for $x$ $=0,0.25,0.5,0.87,1$ ) or three (for $x=0.7,0.75,0.8$ ) different chemical environments. The majority of the Fe ions $(98.4 \%$ for $x=0,89.6 \%$ for $x=0.25,92.7 \%$ for $x=0.5,95.5 \%$ for $x$ $=0.7,82.5 \%$ for $x=0.75,95.7 \%$ for $x=0.8,94.3 \%$ for $x$ $=0.87$, and $95.3 \%$ for $x=1)$ are having CS between -0.22 and $-0.25 \mathrm{~mm} / \mathrm{sec}$. This component is shown by a bigger doublet in the fitted spectra. These values of CS correspond to the low-spin state of $\mathrm{Fe}^{3+}$ ions $\left(S=\frac{1}{2}\right)$ as similar values of CS $(-0.168,-0.15$ and $-0.15 \mathrm{~mm} / \mathrm{sec})$ were found for the low-spin $\mathrm{Fe}^{3+}$ ions in the $\mathrm{Fe}\left[\mathrm{Fe}(\mathrm{CN})_{6}\right] \cdot 4 \mathrm{H}_{2} \mathrm{O}$, $\mathrm{Cu}_{1.5}\left[\mathrm{Fe}(\mathrm{CN})_{6}\right] \cdot 6 \mathrm{H}_{2} \mathrm{O}$, and $\mathrm{K}_{0.2} \mathrm{Co}_{1.4}\left[\mathrm{Fe}(\mathrm{CN})_{6}\right] \cdot 7 \mathrm{H}_{2} \mathrm{O}$ compounds, respectively. ${ }^{11,26,27}$ On the other hand, few Fe ions (1.6\% for $x=0,10.4 \%$ for $x=0.25,3.3 \%$ for $x=0.5,2.5 \%$ for $x=0.7,8 \%$ for $x=0.75,2.3 \%$ for $x=0.8,5.7 \%$ for $x=0.87$, and $4.7 \%$ for $x=1$ ) are having CS between 0.20 and $0.28 \mathrm{~mm} / \mathrm{sec}$. This component is shown as a smaller doublet 


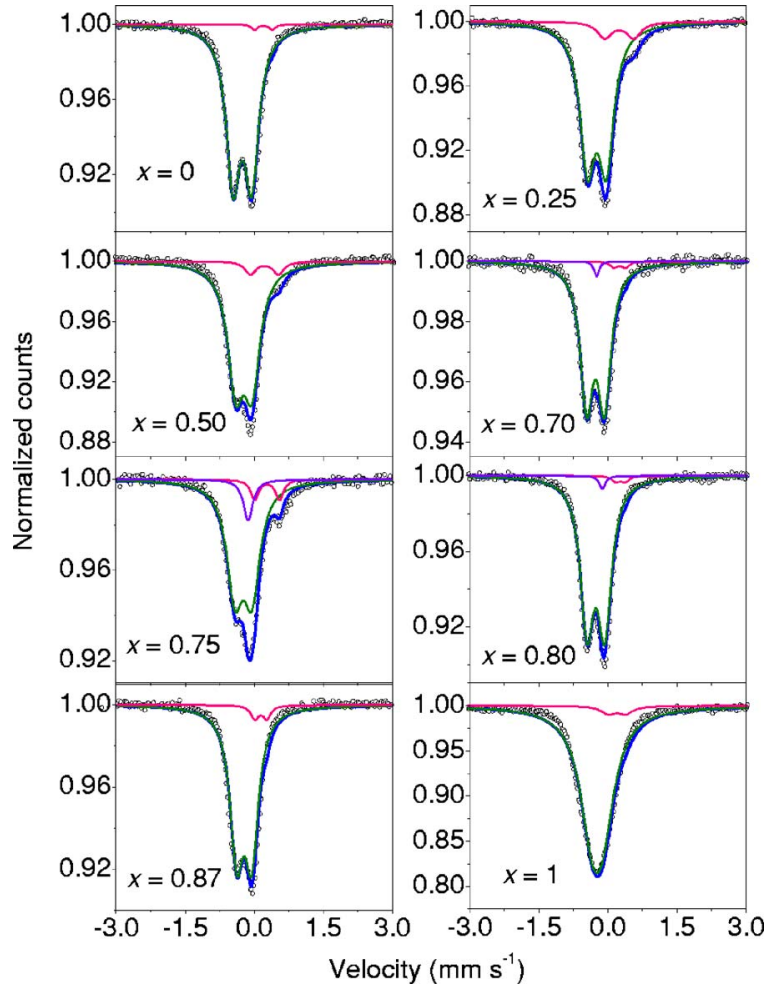

FIG. 4. (Color online) Least-square-fitted Mössbauer spectra for the compounds at room temperature. A $50-\mathrm{mC}{ }^{57} \mathrm{Co}: \mathrm{Rh}$ Mössbauer source, always kept at room temperature, has been used for the measurements.

in the fitted spectra. These values of CS correspond to the high-spin state of $\mathrm{Fe}^{3+}$ ions $\left(S=\frac{5}{2}\right)$ as similar values of CS $(0.237$ and $0.19 \mathrm{~mm} / \mathrm{sec})$ are found for the high-spin $\mathrm{Fe}^{3+}$ ions in the $\mathrm{Fe}\left[\mathrm{Fe}(\mathrm{CN})_{6}\right] \cdot 4 \mathrm{H}_{2} \mathrm{O}$ and $\mathrm{K}_{0.2} \mathrm{Co}_{1.4}\left[\mathrm{Fe}(\mathrm{CN})_{6}\right] \cdot 7 \mathrm{H}_{2} \mathrm{O}$ compounds, respectively. ${ }^{11,27}$ In addition to the two doublets, a singlet (CS between -0.12 and $-0.16 \mathrm{~mm} / \mathrm{sec}$ ) also appears with $2 \%, 9.5 \%$, and $2 \%$ fraction for the $x=0.7,0.75$, and 0.8 compositions, respectively. This singlet may be assigned to the low-spin $\mathrm{Fe}^{2+}$ $(S=0)$ in the form of $\mathrm{Fe}^{2+}-\mathrm{CN}_{-} \mathrm{Co}^{3+} / \mathrm{Ni}^{3+}$-type linear chains as observed in the $\mathrm{Cu}_{1.5}\left[\mathrm{Fe}(\mathrm{CN})_{6}\right] \cdot 6 \mathrm{H}_{2} \mathrm{O}$ and $\quad \mathrm{K}_{0.2} \mathrm{Co}_{1.4}\left[\mathrm{Fe}(\mathrm{CN})_{6}\right] \cdot 7 \mathrm{H}_{2} \mathrm{O}$ compounds (CS $\sim-0.07 \mathrm{~mm} / \mathrm{sec}){ }^{26,27}$ It may be noted that a small differ- ence of $\sim 0.05$ to $0.1 \mathrm{~mm} / \mathrm{s}$ existing in the reported ${ }^{26,27} \mathrm{CS}$ values and our CS values for the three components of the Mössbauer spectra arises due to the reasons like difference in the chemical composition of the compounds used in the literature ${ }^{26,27}$ and used by us for the study, a possible difference in the Mössbauer source matrix used in the two cases (the Mössbauer source used in Refs. 26 and 27 is unspecified) and a small ambiguity which normally exists in fitting a low intensity Mössbauer component, etc., and thus is understandable. In this way, the Mössbauer results show that the majority of the $\mathrm{Fe}$ ions are in the low-spin $\mathrm{Fe}^{3+}$ state, i.e., connected to the $\mathrm{C}$ end of the $\mathrm{CN}$ ion in the form of $\mathrm{Fe}^{3+}-\mathrm{CN}-\mathrm{Co}^{2+} / \mathrm{Ni}^{2+}-\mathrm{NC}-\mathrm{Fe}^{3+}$ linear chains. However, a few $\mathrm{Fe}$ ions are in the high-spin $\mathrm{Fe}^{3+}$ state and connected to the $\mathrm{N}$ end of the $\mathrm{CN}$ ion in the form of $\mathrm{Fe}^{3+}-\mathrm{NC}-\mathrm{Co}^{2+} / \mathrm{Ni}^{2+}-\mathrm{CN}-\mathrm{Fe}^{3+}$ linear chains. The occurrence of the latter type of chains in these compounds is a structural defect. An additional structural defect is found for the compositions around the $x=0.75$ where the $\mathrm{Fe}$ ions are found in the low-spin $\mathrm{Fe}^{2+}$ state in the form of $\mathrm{Fe}^{2+}-\mathrm{CN}-\mathrm{Co}^{3+} / \mathrm{Ni}^{3+}$ linear chains. The observed dip in the lattice parameter around the $x=0.75$ composition may be explained by the presence of $\mathrm{Fe}^{2+}-\mathrm{CN}-\mathrm{Co}^{3+} / \mathrm{Ni}^{3+}$-type linear chains around that composition. It is known that the lattice parameters for the Ni/Co ferrocyanides are smaller by $0.15-0.4 \AA$ with respect to the corresponding Ni/Co ferricyanides. ${ }^{28,29}$ Therefore the presence of the $\mathrm{Fe}^{2+}-\mathrm{CN}-\mathrm{Co}^{3+} / \mathrm{Ni}^{3+}$-type linear chains around the $x=0.75$ composition reduces the lattice parameter to a lower value in the series. The results of the Mössbauer spectra analysis therefore hint toward disordered structures for the compounds of the present series. This kind of disorder is also seen in the other compounds of the PBA family. ${ }^{26,27,30}$ This disorder may greatly affect the structural and magnetic properties of the PBA compounds. We will discuss this point, in detail, later.

\section{IR spectra studies}

Another evidence of the structural disorder is obtained from the IR spectra recorded in the $1900-2300-\mathrm{cm}^{-1}$ range. The PBA compounds are well characterized by their $\mathrm{CN}$ stretching frequencies in the 2000-2200- $\mathrm{cm}^{-1}$ range. ${ }^{26,27,30-32}$ The IR spectra at room temperature for the studied compounds are depicted in Fig. 5 and the values of

TABLE I. Mössbauer parameters for the compounds of the series.

\begin{tabular}{|c|c|c|c|c|c|c|c|c|c|c|c|}
\hline$x$ & $\begin{array}{c}\mathrm{CS} 1 \\
(\mathrm{~mm} / \mathrm{s})\end{array}$ & $\begin{array}{c}\text { QS1 } \\
(\mathrm{mm} / \mathrm{s})\end{array}$ & $\begin{array}{l}\text { WDT1 } \\
(\mathrm{mm} / \mathrm{s})\end{array}$ & $\begin{array}{c}\mathrm{CS} 2 \\
(\mathrm{~mm} / \mathrm{s})\end{array}$ & $\begin{array}{c}\text { QS2 } \\
(\mathrm{mm} / \mathrm{s})\end{array}$ & $\begin{array}{l}\text { WDT2 } \\
(\mathrm{mm} / \mathrm{s})\end{array}$ & $\begin{array}{c}\text { CS3 } \\
(\mathrm{mm} / \mathrm{s})\end{array}$ & $\begin{array}{l}\text { WDT3 } \\
(\mathrm{mm} / \mathrm{s})\end{array}$ & $\begin{array}{c}\text { INT1 } \\
(\%)\end{array}$ & $\begin{array}{c}\text { INT2 } \\
(\%)\end{array}$ & $\begin{array}{c}\text { INT3 } \\
(\%)\end{array}$ \\
\hline 0.0 & -0.248 & 0.407 & 0.367 & 0.208 & 0.391 & 0.158 & & & 98.4 & 1.6 & \\
\hline 0.25 & -0.230 & 0.409 & 0.401 & 0.257 & 0.633 & 0.383 & & & 89.6 & 10.4 & \\
\hline 0.50 & -0.223 & 0.347 & 0.420 & 0.230 & 0.610 & 0.289 & & & 92.7 & 7.3 & \\
\hline 0.70 & -0.239 & 0.393 & 0.343 & 0.261 & 0.261 & 0.207 & -0.145 & 0.131 & 95.5 & 2.5 & 2.0 \\
\hline 0.75 & -0.229 & 0.368 & 0.425 & 0.287 & 0.540 & 0.208 & -0.138 & 0.247 & 82.5 & 8.0 & 9.5 \\
\hline 0.80 & -0.247 & 0.386 & 0.349 & 0.287 & 0.208 & 0.211 & -0.122 & 0.120 & 95.7 & 2.3 & 2.0 \\
\hline 0.87 & -0.234 & 0.365 & 0.308 & 0.261 & 0.327 & 0.298 & & & 94.3 & 5.7 & \\
\hline 1.00 & -0.227 & 0.235 & 0.639 & 0.208 & 0.378 & 0.403 & & & 95.3 & 4.7 & \\
\hline
\end{tabular}




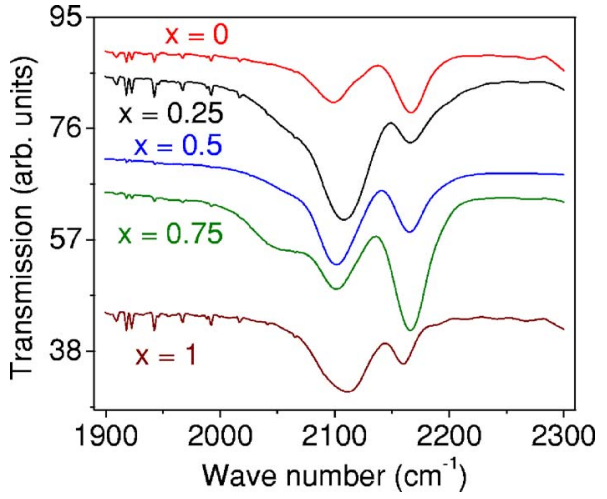

FIG. 5. (Color online) IR spectrum showing the $\mathrm{CN}$ stretching frequencies. The curves have been shifted relative to the $x=0$ curve for better visibility.

the CN stretching frequencies are listed in Table II. The IR spectra of the compounds show two main absorptions around 2165 and $2101 \mathrm{~cm}^{-1}$. These two $\mathrm{CN}$ stretching frequencies correspond to the presence of the low-spin $\mathrm{Fe}^{3+}$ (i.e., $\mathrm{Fe}^{3+}-\mathrm{CN}-\mathrm{Co}^{2+} / \mathrm{Ni}^{2+}$-type linear chains) and the high-spin $\mathrm{Fe}^{3+}$ (i.e., $\mathrm{Fe}^{3+}-\mathrm{NC}-\mathrm{Co}^{2+} / \mathrm{Ni}^{2+}$-type linear chains) ions, respectively, in these compounds. Similar values of the $\mathrm{CN}$ stretching frequencies for the low- and high-spin $\mathrm{Fe}^{3+}$ ions in the octahedral environment were found in the $\mathrm{Cu}_{1.5}\left[\mathrm{Fe}(\mathrm{CN})_{6}\right] \cdot 6 \mathrm{H}_{2} \mathrm{O}$ and $\mathrm{K}_{0.2} \mathrm{Co}_{1.4}\left[\mathrm{Fe}(\mathrm{CN})_{6}\right] \cdot 7 \mathrm{H}_{2} \mathrm{O}$ compounds, respectively. ${ }^{26,27}$ However, the IR spectrum for the $x=0.75$ compound has one more absorption around $2055 \mathrm{~cm}^{-1}$. This absorption indicates the presence of the low-spin $\mathrm{Fe}^{2+}$ (i.e., $\mathrm{Fe}^{2+}-\mathrm{CN}-\mathrm{Co}^{3+} / \mathrm{Ni}^{3+}$ ) in this compound as similar values of the stretching frequencies for the lowspin $\mathrm{Fe}^{2+}$ ions were found in the $\mathrm{Cu}_{1.5}\left[\mathrm{Fe}(\mathrm{CN})_{6}\right] \cdot 6 \mathrm{H}_{2} \mathrm{O}$, $\mathrm{K}_{0.2} \mathrm{Co}_{1.4}\left[\mathrm{Fe}(\mathrm{CN})_{6}\right] \cdot 7 \mathrm{H}_{2} \mathrm{O}$, and $\mathrm{Mn}_{2}\left[\mathrm{Fe}(\mathrm{CN})_{6}\right] \cdot 8 \mathrm{H}_{2} \mathrm{O}$ compounds. $26,27,32$ Therefore the results obtained from the IR studies are consistent with the Mössbauer studies and these indicate the disordered structure for the compounds of the series. The effect of this kind of disorder on the local structure is discussed in the next section.

\section{Reverse Monte Carlo modeling of the neutron data}

There are two main sources of structural disorder in these compounds: first the partial occupancies of the $\mathrm{Fe}(\mathrm{CN})_{6}$ units and uncoordinated water molecules and, second the oc-

TABLE II. Cyanide stretching frequencies of the compounds at room temperature.

\begin{tabular}{lccc}
\hline \hline & \multicolumn{3}{c}{ CN stretching frequencies } \\
\cline { 2 - 4 } Composition $(x)$ & $f_{1}\left(\mathrm{~cm}^{-1}\right)$ & $f_{2}\left(\mathrm{~cm}^{-1}\right)$ & $f_{3}\left(\mathrm{~cm}^{-1}\right)$ \\
\hline 0 & 2166.8 & 2099.3 & \\
0.25 & 2165.9 & 2108.0 & \\
0.50 & 2164.9 & 2101.2 & \\
0.75 & 2165.9 & 2101.2 & 2055 \\
1.00 & 2160.1 & 2110.9 & \\
\hline \hline
\end{tabular}

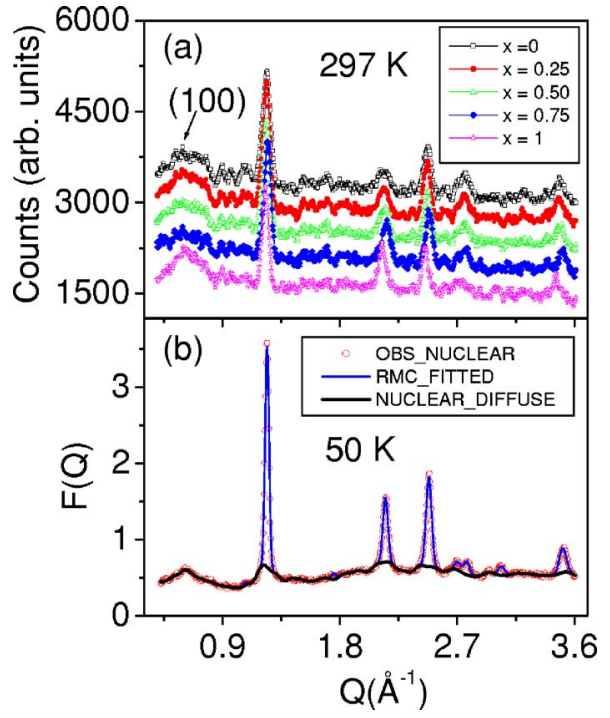

FIG. 6. (Color online) (a) Room-temperature neutron-diffraction patterns of the compounds. The patterns are shifted relative to each other for easy viewing. First broad peak at the (100) position is forbidden under the $F m 3 m$ space group. (b) RMC fitted pattern at $50 \mathrm{~K}$ for $\mathrm{Co}_{1.125} \mathrm{Ni}_{0.375}\left[\mathrm{Fe}(\mathrm{CN})_{6}\right] \cdot z \mathrm{H}_{2} \mathrm{O}$ compound. $F(Q)$ is the sum of the scattering amplitudes in the reciprocal space at a given $Q$ value from all the atoms. Observed data are represented by open circles and the Bragg intensities are shown by thin solid line. Thick solid line shows the nuclear diffuse scattering contribution.

cupation of the $(0,0,0)$ site by both the $\mathrm{Co}^{2+}$ and $\mathrm{Ni}^{2+}$ ions. The number of the $\mathrm{Fe}(\mathrm{CN})_{6}$ vacancies and the position of water molecules in the unit cell of the PBAs, $A_{m}\left[B(\mathrm{CN})_{6}\right]_{n} \cdot z \mathrm{H}_{2} \mathrm{O}$, depend on the $m / n$ ratio. ${ }^{11}$ For $m / n$ $=1$, there are no $\left[\mathrm{Fe}(\mathrm{CN})_{6}\right]$ vacancies and the water molecules occupy the interstitial ( $8 c$ and $32 f)$ sites. However, when the $m / n>1$ (for the present series $m / n>1.5$ ), there are $\mathrm{Fe}(\mathrm{CN})_{6}$ vacancies, which are occupied by the $\mathrm{O}$ atoms of the coordinated water molecules at the empty $\mathrm{N}$ site $(24 e)$. In the latter case, the remaining water molecules (the uncoordinated water molecules) occupy the interstitial ( $8 c$ and $32 f)$ sites. However, the occupancies of the interstitial water molecule sites in both cases are partial $(33 \%$ and $7 \%$, respectively). All the above kinds of disorders are static in nature and appear as a diffuse scattering in the diffraction patterns as it is evident from the room-temperature neutrondiffraction patterns of the compounds shown in Fig. 6(a). The diffraction patterns also have a broad peaklike feature at the (100) Bragg position which is forbidden in the facecentred space group $F m 3 \mathrm{~m}$. The Rietveld refinement technique can only give the averaged structural information and it is not suitable for analyzing the local defects. In our earlier paper $^{21}$ on $\mathrm{Co}_{0.375} \mathrm{Ni}_{1.125}\left[\mathrm{Fe}(\mathrm{CN})_{6}\right] \cdot z \mathrm{H}_{2} \mathrm{O}(x=0.25)$, we analyzed these structural defects using the reverse Monte Carlo (RMC) based program, RMCPOW. ${ }^{33}$ In the present study, we show that the signatures of such structural defects are present in all compositions of the series [Fig. 6(a)] and as an example, we present here the results of the RMC modeling of the diffuse scattering for the $x=0.75$ composition.

The RMCPOW is a general purpose FORTRAN code for the RMC modeling of static and dynamic disorder in crystalline 
materials using powder-diffraction data. Starting from configurations corresponding to the average crystal structure (as obtained from, e.g., Rietveld methods), the method can be used to refine the local structure. ${ }^{33}$ The detailed description of the program can be obtained from the website given in Ref. 33. To analyze the diffuse scattering present in the diffraction patterns of the compound $\mathrm{Co}_{1.125} \mathrm{Ni}_{0.375}\left[\mathrm{Fe}(\mathrm{CN})_{6}\right] \cdot z \mathrm{H}_{2} \mathrm{O}(x=0.75)$, high-resolution and high intensity neutron-diffraction data were recorded at PSI. The output of the Rietveld refinement for the diffraction pattern of the compound was taken as an input for the RMC modeling. The observed data were also corrected for the paramagnetic scattering. The output of the RMCPOW program is plotted in Fig. 6(b). The observed nuclear diffuse scattering is able to fit the unindexed peak at the (100) Bragg position. The analysis of the pair-correlation functions reveals that the occupation of the $\mathrm{O}$ atoms at the empty $\mathrm{Fe}(\mathrm{CN})_{6}$ sites is not random but is partially correlated which gives rise to the unindexed peak at the (100) Bragg position. The analysis also indicated a random distribution of the $\mathrm{Co} / \mathrm{Ni}$ ions at the $(0,0,0)$ site and the presence of the $\mathrm{Fe}, \mathrm{Co}$, and $\mathrm{Ni}$ ions at both the $(0,0,0)$ and $\left(\frac{1}{2}, \frac{1}{2}, \frac{1}{2}\right)$ sites. We also note that the distribution of metal ions in these crystallographic sites is consistent with the results obtained in the Mössbauer and IR spectra studies. Since the unindexed peak at the (100) Bragg position arises due to the partially correlated (few) oxygen atoms, it is not visible in the x-ray-diffraction patterns as the number of oxygen atoms contributing to this feature is quite low. Moreover, the contributions from the oxygen atoms are negligible in the presence of metal $(\mathrm{Co} / \mathrm{Ni} / \mathrm{Fe})$ ions as the former $(Z=8)$ has low scattering power $\left(\propto Z^{2}\right)$ compared to the metal ions $\left(Z_{\mathrm{Fe}}=26, Z_{\mathrm{Co}}=27\right.$, and $\left.Z_{\mathrm{Ni}}=28\right), Z$ being the atomic number. In the case of neutrons, however, because of the comparable scattering powers $\left(\propto b^{2}\right)$ of the oxygen $(b=0.5803 \mathrm{fm})$ and metal ions $\left(b_{\mathrm{Fe}}=0.945 \mathrm{fm}, b_{\mathrm{Co}}=0.249 \mathrm{fm}\right.$, and $\left.b_{\mathrm{Ni}}=1.03 \mathrm{fm}\right)$ where $b$ is the coherent scattering length, the feature due to partial ordering of oxygen atoms is observed. A two-dimensional (2D) plot of the oxygen atoms of the coordinated water molecules in the (100) plane of a $4 a \times 4 a \times 4 a$ configurational cell is shown in Fig. 7. The clustering of the oxygen atoms perpendicular to crystallographic $a$ axis is quite evident. Therefore the results of the RMC modeling of diffuse scattering in the neutron-diffraction pattern of the $\mathrm{Co}_{1.125} \mathrm{Ni}_{0.375}\left[\mathrm{Fe}(\mathrm{CN})_{6}\right] \cdot z \mathrm{H}_{2} \mathrm{O}(x=0.75)$ compound are consistent with our earlier neutron-diffraction studies on the $\mathrm{Co}_{0.375} \mathrm{Ni}_{1.125}\left[\mathrm{Fe}(\mathrm{CN})_{6}\right] \cdot z \mathrm{H}_{2} \mathrm{O} \quad(x=0.25) \quad$ compound. This kind of local ordering of the oxygen atoms is also reported in the powder sample of $\mathrm{Mn}_{2}\left[\mathrm{Mn}(\mathrm{CN})_{6}\right]_{2} \cdot z \mathrm{H}_{2} \mathrm{O}$ and is a manifestation of disordered structure of these compounds. ${ }^{7}$ The effects of these disorders on the magnetic properties of these compounds are discussed in the next section.

\section{E. dc magnetization and neutron-diffraction studies}

Figure 8(a) depicts the field-cooled magnetization $\left(M_{F C}\right)$ vs temperature $(T)$ curves at 200 Oe for the compounds of the series. Variation of $T_{C}$, derived from the minimum of $d M / d T$ vs $T$ curves of the respective compounds, as a func-

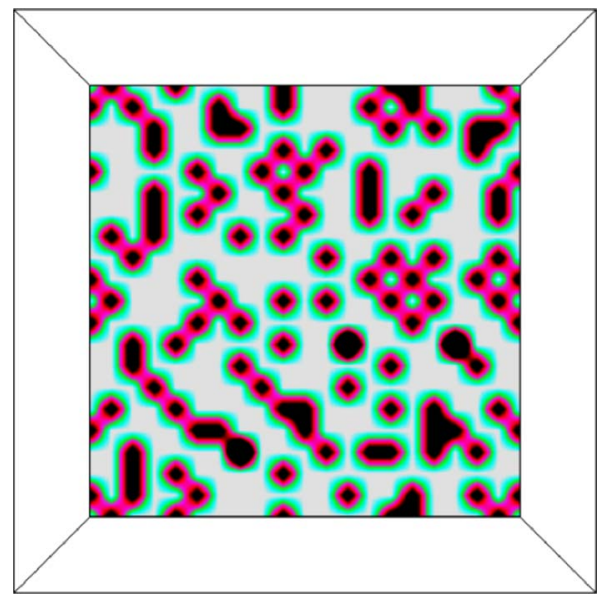

FIG. 7. (Color online) 2D plot of the coordinated oxygen atoms in $\mathrm{Co}_{1.125} \mathrm{Ni}_{0.375}\left[\mathrm{Fe}(\mathrm{CN})_{6}\right] \cdot z \mathrm{H}_{2} \mathrm{O}$ showing the clustering of the oxygen atoms perpendicular to the (100) axis in a $4 a \times 4 a \times 4 a$ configuration cell. The density of the oxygen atoms is maximum at the center (black color) and it decreases towards the periphery (cyan color in the online version).

tion of the composition $(x)$ is shown in Fig. 8(b). It is evident from the plots that $T_{C}$ does not vary linearly with the composition but has a minima corresponding to $\sim 80 \%$ Co doping in the parent compound, $\mathrm{Ni}_{1.5}\left[(\mathrm{CN})_{6}\right] \cdot z \mathrm{H}_{2} \mathrm{O}$. The occurrence of the minimum can be understood from the results obtained from the IR and Mössbauer studies. The IR and Mössbauer studied have shown the presence of noninteracting $\mathrm{Fe}^{2+}-\mathrm{CN}-\mathrm{Co}^{3+} / \mathrm{Ni}^{3+}$ linear chains in the compounds having $x$ around 0.75 . These chains are noninteracting because
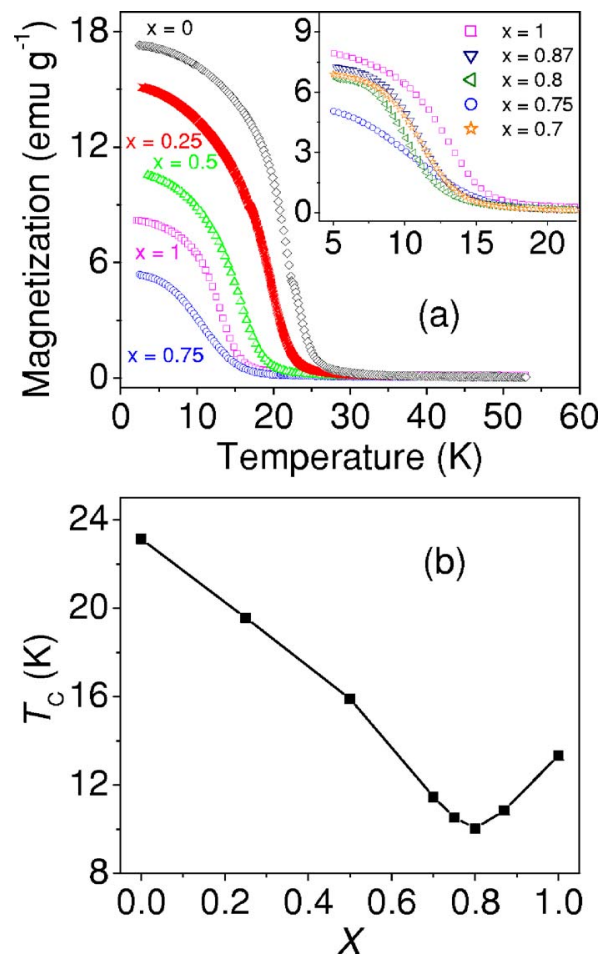

FIG. 8. (Color online) (a) $M_{F C}$ vs $T$ curves at 200 Oe (b) variation of $T_{C}$ with the composition $(x)$. 


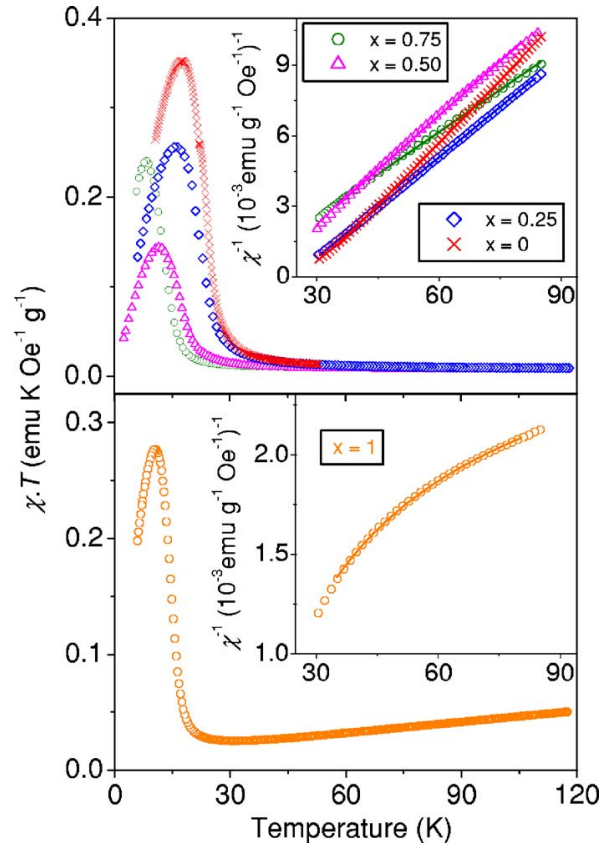

FIG. 9. (Color online) $\chi \cdot T$ vs $T$ curves between 120 and $5 \mathrm{~K}$. The insets show the linear fitting of the $\chi$ vs $T$ curves in the $35-80-\mathrm{K}$ range.

of the diamagnetic low-spin $\mathrm{Fe}^{2+}$ and low-spin $\mathrm{Co}^{3+}$ ions. Therefore these chains do not participate in the propagation of magnetic interactions through them and hence $T_{C}$ dips for the compounds around the $x=0.75$. Figure 9 shows the $\chi \cdot T$ vs $T$ curves in the $5-120-\mathrm{K}$ range, where $\chi$ is the dc susceptibility. For a typical ferromagnet, the $\chi \cdot T$ vs $T$ curve rises continuously with the lowering of $T$ till $T_{C}$ is reached. However, for a ferrimagnet, the $\chi \cdot T$ vs $T$ curve shows a minimum before rising to a maximum around $T_{N} \cdot{ }^{12,30,34}$ Among the various compounds of the series, the $\chi \cdot T$ vs $T$ curve only for the $\mathrm{Co}_{1.5}\left[\mathrm{Fe}(\mathrm{CN})_{6}\right] \cdot z \mathrm{H}_{2} \mathrm{O}$ compound shows a minimum for $T<T_{C}$. This indicates that all the compounds of the series (except the $x=1$ ) are ferromagnet and the compound with $x$ $=1$ is a ferrimagnet. The insets in Fig. 9 show the $\chi^{-1}$ vs $T$ curves. These curves, except for the $x=1$, are fitted with the Curie-Weiss law

$$
\chi^{-1}=\frac{T-\Theta}{C}
$$

in the temperature range $35-80 \mathrm{~K}$. The inverse susceptibility curve for the $\mathrm{Co}_{1.5}\left[\mathrm{Fe}(\mathrm{CN})_{6}\right] \cdot z \mathrm{H}_{2} \mathrm{O} \quad(x=1)$ compound has been found to obey the parabolic equation ${ }^{30,35,36}$

$$
\chi^{-1}=\frac{T-\Theta}{C}-\frac{1}{D\left(T-\Theta_{1}\right)} .
$$

The values of derived fitting parameters (the Curie constant $C$, the paramagnetic Curie temperature $\Theta$, and the experimentally observed effective paramagnetic moment $\mu_{\text {eff }}$ ) along with the theoretically expected spin only $\mu_{\text {eff }}$ are shown in Table III. The positive values of the $\Theta$ for all the compounds, except for the $x=1$, indicate positive exchange correlations among the $\mathrm{Co}, \mathrm{Ni}$, and $\mathrm{Fe}$ ions. For $x=1$, a nega-
TABLE III. Values of paramagnetic Curie temperature, Curie constant, and effective paramagnetic moments.

\begin{tabular}{lcccc}
\hline \hline$x$ & $\begin{array}{c}\text { Curie temp. } \\
(\mathrm{K})\end{array}$ & $\begin{array}{c}\text { Curie constant } \\
(\mathrm{emu} \text { K/Oe/g) }\end{array}$ & $\begin{array}{c}\text { Observed } \mu_{\text {eff }} \\
\left(\mu_{\mathrm{B}} / \text { f.u. }\right)\end{array}$ & $\begin{array}{c}\text { Theoretical } \mu_{\text {eff }} \\
\left(\mu_{\mathrm{B}} / \text { f.u. }\right)\end{array}$ \\
\hline 0 & $27.61(1)$ & $0.005560(3)$ & 4.20 & 3.94 \\
0.25 & $24.164(4)$ & $0.007020(1)$ & 4.91 & 4.06 \\
0.50 & $17.15(3)$ & $0.006130(7)$ & 4.55 & 3.91 \\
0.7 & $13.08(1)$ & $0.00545(4)$ & 4.27 & 3.23 \\
0.75 & $8.38(5)$ & $0.008360(9)$ & 5.36 & 3.64 \\
0.8 & $10.86(2)$ & $0.00863(8)$ & 5.37 & 3.10 \\
0.87 & $10.80(2)$ & $0.0091(8)$ & 5.51 & 3.21 \\
1 & $-57.21(1)$ & $0.00952(5)$ & 5.64 & 5.14 \\
\hline \hline
\end{tabular}

tive value of $\Theta$ indicates negative exchange correlations between the $\mathrm{Co}$ and $\mathrm{Fe}$ ions. In the calculation of the theoretical $\mu_{\text {eff }}$ for all the compositions $(x)$, spin states of the Fe ions and its concentration derived from the Mössbauer spectra analysis are taken. In all the calculations, the $\mathrm{Ni}^{2+}$ ions with $S=1$ spin state are considered as $\mathrm{Ni}^{2+}\left(3 d^{8}=t_{2 g}^{6} e_{g}^{2}\right)$ can have only the $S=1$ spin state in both the C (low-spin) and N (highspin) coordination. ${ }^{12}$ For the $\mathrm{Co}^{2+}$ ion, a low-spin state $(S$ $=\frac{1}{2}$ ) is assumed (except for $x=1$ ) in both $\mathrm{C}$ and $\mathrm{N}$ coordination. ${ }^{12}$ However, for the $x=0.7,0.75$, and 0.80 compositions, the theoretical $\mu_{\text {eff }}$ has been calculated by taking the low-spin $\mathrm{Co}^{3+}(S=0)$ and the $\mathrm{Ni}^{3+}$ with $S=\frac{1}{2}$ spin state for the noninteracting linear chains $\mathrm{Fe}^{2+}{ }_{-} \mathrm{CN}-\mathrm{Co}^{3+} / \mathrm{Ni}^{3+}$ (in addition to the low-spin $\mathrm{Co}^{2+}$ and $\mathrm{Ni}^{2+}$ spin states as stated above). For the $x=1$ composition, $95.3 \% \mathrm{Fe}^{3+}-\mathrm{CN}_{-} \mathrm{Co}^{2+}$ chains with the high-spin of $\mathrm{Co}^{2+}\left(S=\frac{3}{2}\right)$ and the low-spin $\mathrm{Fe}^{3+}\left(S=\frac{1}{2}\right)$ and remaining $4.7 \% \mathrm{Fe}^{3+}-\mathrm{NC}-\mathrm{Co}^{2+}$ chains with the low-spin state of $\mathrm{Co}^{2+}\left(S=\frac{1}{2}\right)$ and the high-spin state of $\mathrm{Fe}^{3+}\left(S=\frac{5}{2}\right)$ have been considered for the calculation of $\mu_{\text {eff }}$. It is evident that the experimentally observed $\mu_{\text {eff }}$ are higher than that obtained by considering spin only values and the difference between the experimentally observed and the theoretical spin only $\mu_{\text {eff }}$ increases with increasing the Co composition $(x)$. It indicates that the orbital moment is not completely quenched for the $\mathrm{Co}^{2+}$ ions in these compounds. A similar kind of behavior was observed in other cobalt iron hexacyanides. ${ }^{12,19,36}$

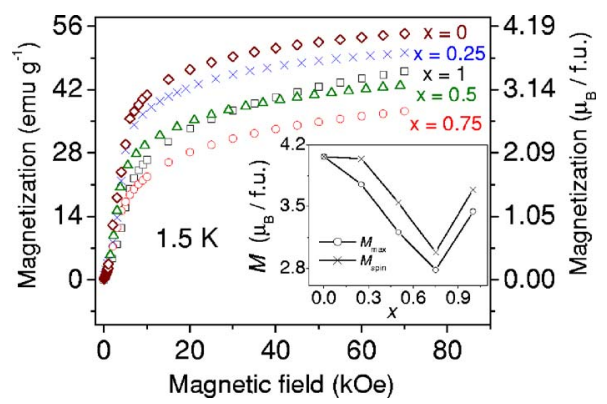

FIG. 10. (Color online) Virgin magnetization curves at $1.5 \mathrm{~K}$. The inset shows the variation of maximum magnetization at $70 \mathrm{kOe}$ and the theoretically expected spin only saturation magnetization as a function of $x$. 


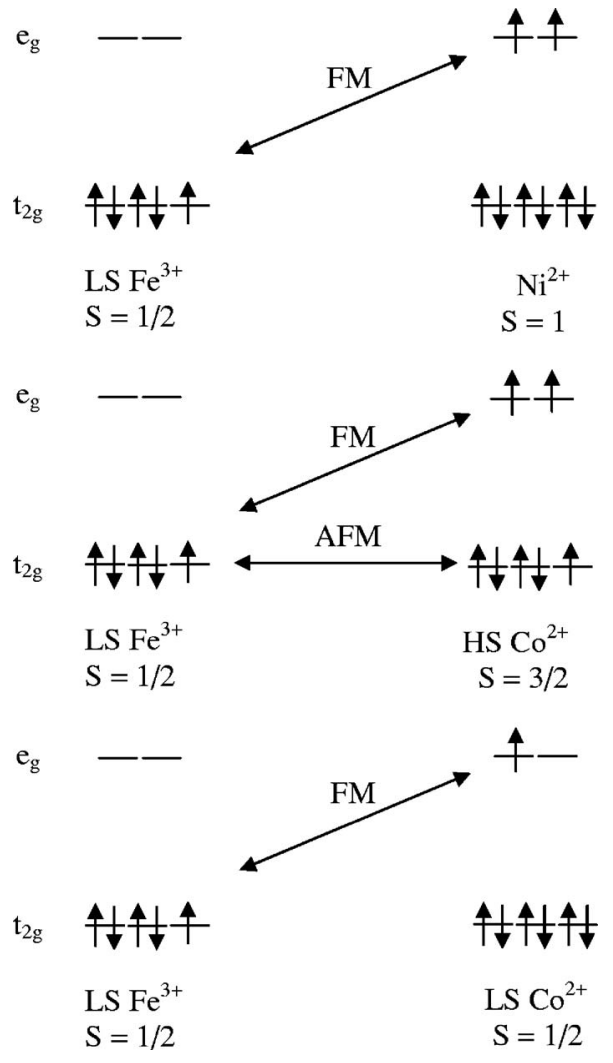

FIG. 11. An illustration of the ferromagnetic (FM) exchange interactions between the low-spin (LS) $\mathrm{Fe}^{3+}$ and $\mathrm{Ni}^{2+}$ and $\mathrm{LS} \mathrm{Fe}{ }^{3+}$ and the $\mathrm{LS} \mathrm{Co}^{2+}$ ions and the antiferromagnetic (AFM) exchange interactions between the $\mathrm{LS} \mathrm{Fe}^{3+}$ and the high-spin (HS) $\mathrm{Co}^{2+}$ ions.

The virgin magnetization curves, at $1.5 \mathrm{~K}$ and up to $70 \mathrm{kOe}$ field, are depicted in Fig. 10. The plots of maximum magnetization $\left(M_{\max }\right)$ at $70 \mathrm{kOe}$ and the theoretically expected spin only saturation magnetization $\left(M_{\text {spin }}\right)$ as a function of composition $(x)$ are shown in the inset. The assumptions for the spin states of various magnetic atoms are similar to those taken for the calculations of $\mu_{\text {eff }}$. The values of the $M_{\max }$ are lower than that for the $M_{\text {spin }}$ because of nonsaturation of magnetization up to 70-kOe field. The effects of structural defects on the variation of $M_{\max }$ can be easily seen as a dip in $M_{\max }$ around $x=0.75$, similar to that observed in the $a$ and $T_{C}$ variation. The sign of magnetic interaction in these compounds also changes from ferrimagnetic for the pure Co based compound to ferromagnetic for the remaining compounds. This transition can be seen as a consequence of a high-spin to a low-spin state transition for the $\mathrm{Co}^{2+}$ ions in the Co-Ni mixed compositions. We know that the magnetic interactions in PBAs are superexchange interactions via $\mathrm{CN}$ bridges. These interactions may be positive (ferromagnetic) or negative (antiferromagnetic or ferrimagnetic) depending upon the symmetries of the magnetic orbitals involved. ${ }^{11,37}$ Superexchange interactions between orthogonal orbitals (e.g., $t_{2 g}$ and $e_{g}$ ) favor a ferromagnetic ordering whereas superexchange interactions between same symmetry orbitals (e.g., $t_{2 g}$ and $t_{2 g}$, and $e_{g}$ and $e_{g}$ ) are antiferromagnetic. A pictorial illustration of various types of magnetic interactions in these compounds is shown in Fig. 11. By considering the
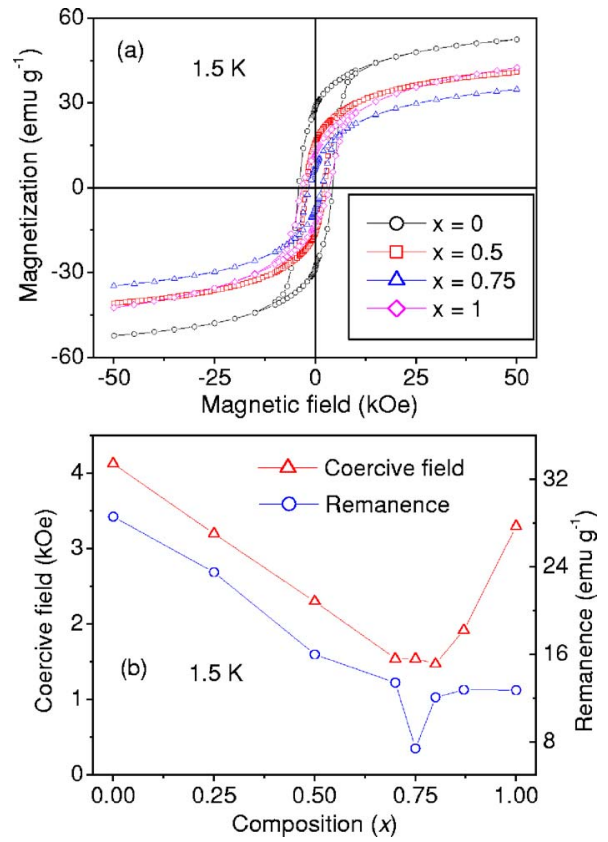

FIG. 12. (Color online) (a) Hysteresis curves at $1.5 \mathrm{~K}$ (b) variation of $H_{C}$ and $M_{R}$ with composition $(x)$. Lines are guide to the eyes.

symmetry of various magnetic orbitals, one can see that the magnetic interactions between the $\mathrm{Ni}^{2+}\left(t_{2 g}^{6} e_{g}^{2}, S=1\right)$ and the low-spin $\mathrm{Fe}^{3+}\left(t_{2 g}^{5} e_{g}^{0}, S=\frac{1}{2}\right)$ will be ferromagnetic and the magnetic interactions between the low-spin $\mathrm{Fe}^{3+}\left(t_{2 g}^{5} e_{g}^{0}, S\right.$ $\left.=\frac{1}{2}\right)$ and low-spin $\mathrm{Co}^{2+}\left(t_{2 g}^{6} e_{g}^{1}, S=\frac{1}{2}\right)$ will be ferromagnetic. The above magnetic interactions explain the ferromagnetic ordering in all (except for the $x=1$ ) compositions of the present series. However, in the case of magnetic interactions between the high-spin $\mathrm{Co}^{2+}\left(t_{2 g}^{5} e_{g}^{2}, S=\frac{3}{2}\right)$ and the low-spin $\mathrm{Fe}^{3+}\left(t_{2 g}^{5} e_{g}^{0}, S=\frac{1}{2}\right)$, both ferromagnetic as well as antiferromagnetic interaction are present but overall, the antiferromagnetic interaction is dominant ${ }^{37}$ and the end compound $(x=1)$ is ferrimagnetic.

The hysteresis curves at $1.5 \mathrm{~K}$ for the selected compounds are shown in Fig. 12(a). The variation of $H_{C}$ and remanence $M_{R}$ as function of composition is shown in Fig. 12(b). The observed $H_{C}$ and $M_{R}$ do not vary linearly with the composition but have a variation similar to $a, T_{C}$, and $M_{\max }$. Both the curves have the lowest values around the $x=0.75$ composition. The structural defects may reduce the spin-orbit coupling present for the Co-doped compounds. This might result in a low magnetocrystalline anisotropy, responsible for the weaker magnetic hardness (lower $H_{C}$ around $x=0.75$ ).

dc magnetization measurements do not give information about the magnetic moments of the individual magnetic atoms. For this purpose, neutron diffraction in the magnetically ordered state (below $T_{C}$ ) could be a very good probe. We recorded low-temperature (50 and $1.5 \mathrm{~K}$ ) neutron-diffraction patterns for few compounds of the series. Figure 13(a) depicts the neutron-diffraction patterns at 50 and $1.5 \mathrm{~K}$ for $\mathrm{Co}_{1.125} \mathrm{Ni}_{0.375}\left[\mathrm{Fe}(\mathrm{CN})_{6}\right] \cdot z \mathrm{H}_{2} \mathrm{O}(x=0.75)$ compound. The difference pattern $(1.5-50 \mathrm{~K})$ is plotted at the bottom. The intensity axis of difference pattern is enlarged in Fig. 13(b). In 

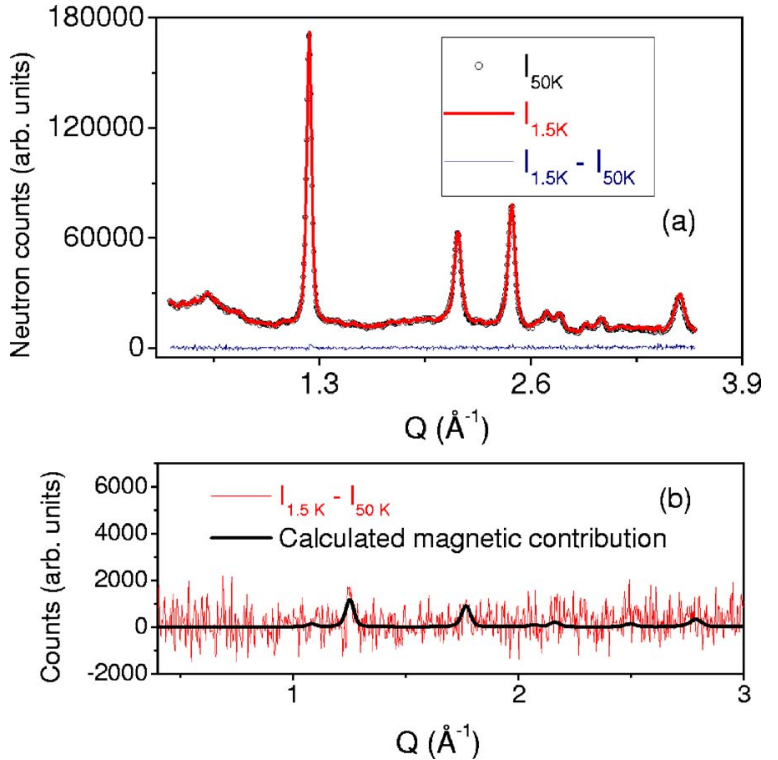

FIG. 13. (Color online) (a) Neutron-diffraction patterns at 1.5 and $50 \mathrm{~K}$ and their difference for the $\mathrm{Co}_{1.125} \mathrm{Ni}_{0.375}\left[\mathrm{Fe}(\mathrm{CN})_{6}\right] \cdot z \mathrm{H}_{2} \mathrm{O}$ compound. (b) An enlarged view of the difference pattern, shown in (a), along with the calculated magnetic contribution.

the same Fig. 13(b), the theoretically expected magnetic scattering contribution from the ferromagnetic ordering of $\mathrm{Co}, \mathrm{Ni}$, and $\mathrm{Fe}$ ionic moments, consistent with the dc magnetization results, is also shown. It is evident from Fig. 13(b) that a negligibly small magnetic contribution is indeed visible (comparable to the calculated magnetic pattern). However, it is also evident from Fig. 14 that the calculated magnetic contribution is more than one order of magnitude smaller than the nuclear diffuse scattering. Therefore it is very difficult to extract any quantitative information from the magnetic signal. The above results hold true for other compounds of the series.

The field cooled and the zero-field-cooled magnetization $\left(M_{\mathrm{FC}}\right.$ and $\left.M_{\mathrm{ZFC}}\right)$ curves are shown in Fig. 15. The minimum field $\left(H_{\mathrm{min}}\right)$ required to suppress the branching between $M_{\mathrm{FC}}$ and $M_{\mathrm{ZFC}}$ down to $5 \mathrm{~K}$ is also plotted for different compositions. The branching between $M_{\mathrm{FC}}$ and $M_{\mathrm{ZFC}}$ is large at smaller fields and diminishes as we increase the field. $H_{\min }$ is

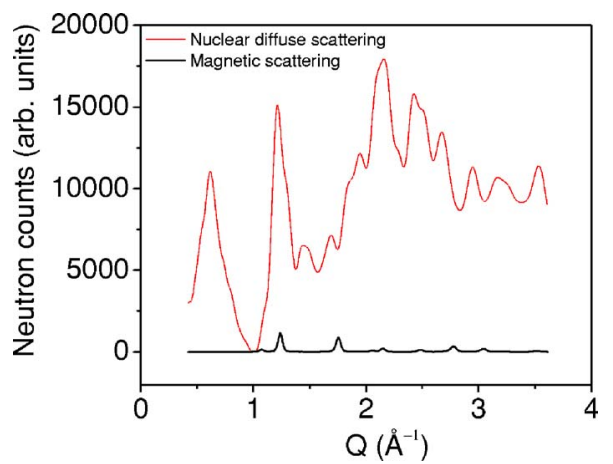

FIG. 14. (Color online) Plots of the nuclear diffuse scattering contribution and the magnetic scattering contribution (model calculation) for the $x=0.75$ composition.
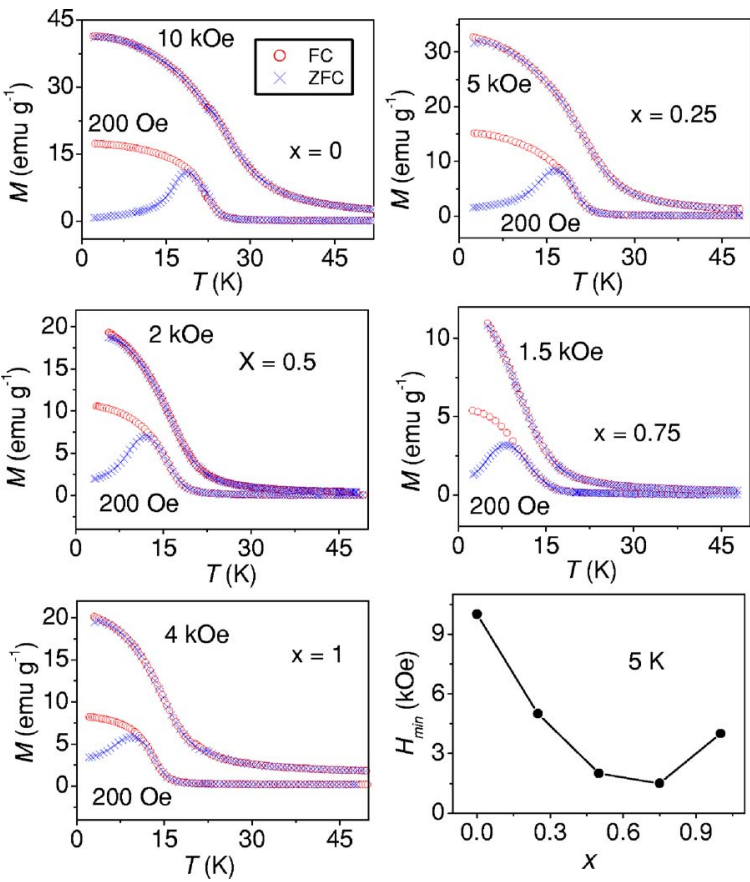

FIG. 15. (Color online) $M_{\mathrm{FC}}(\bigcirc)$ and $M_{\mathrm{ZFC}}(\times)$ curves between 5 and $50 \mathrm{~K} . H_{\min }$ is also plotted for different compositions at $5 \mathrm{~K}$.

different for different compounds of the series but it shows a behavior similar to the $T_{C}$ and $H_{C}$ variation. It may be mentioned here that the plot of $H_{\min }$ vs $x$ merely shows the trend as the field step between the two measurements was of the order of $1 \mathrm{kOe}$. Nevertheless, this observation indicates a possible relationship between magnetic irreversibility and magnetic hardness. This type of branching between $M_{\mathrm{FC}}$ and $M_{\mathrm{ZFC}}$ curves is very common in spin glass, ${ }^{38-42}$ cluster spin glass, ${ }^{43,44}$ and superparamagnets. ${ }^{45-47}$ However, for the present ferromagnetic or ferrimagnetic systems where longrange magnetic ordering is involved, the branching can occur due to domain-wall motions and disorders ${ }^{48-51}$ too. Let us first discuss the effects of magnetic domain-wall motions, under different cooling conditions, on the magnetic irreversibility. Cooling under the applied magnetic field favors domain growth in the direction of applied field and hence a higher magnetization in this case. On the other hand, domain growth will be random in the case of zero-field cooling and will be dictated by magnetocrystalline anisotropy. This fact also suggests that a compound with low magnetocrystalline anisotropy (i.e., low $H_{C}$ ) will require a lower field to suppress the irreversibility between $M_{\mathrm{FC}}$ and $M_{\mathrm{ZFC}}$. The other reason for the observed branching could be due to the inherent structural disorder present in these compounds. It is evident from our structural studies that the partial occupancies of the $\mathrm{Fe}(\mathrm{CN})_{6}$ units and uncoordinated water molecules and the random distribution of the $\mathrm{Co}, \mathrm{Ni}$, and $\mathrm{Fe}$ ions at the $4 a$ $(0,0,0)$ and $4 b\left(\frac{1}{2}, \frac{1}{2}, \frac{1}{2}\right)$ sites contribute to the structural disorders in these compounds. Therefore all these structural defects also contribute to the observed branching between the FC and ZFC magnetization curves.

The spin states of the magnetic ions in the present series and the structural defects are very much interrelated. Especially, the spin states of the Co ions are very much dependent 
on ligand field strength. ${ }^{52}$ Due to the off-stoichiometry of the compounds of the series, there are $\mathrm{Fe}(\mathrm{CN})_{6}$ vacancies. These vacancies are filled by the water molecules. In the presence of water molecules, the first coordination sphere of the Co ions is $\left[(\mathrm{NC})_{6-\mathrm{n}}\left(\mathrm{OH}_{2}\right)_{\mathrm{n}}\right]$, where $n$ may vary from 1 to 5 . Therefore due to the variable amount of structural disorder (depending upon " $n$ "), the ligand field strength at the Co ion site changes and it causes $\mathrm{Co}^{2+}(\mathrm{HS})-\mathrm{NC}-\mathrm{Fe}^{3+}(\mathrm{LS})$ linear

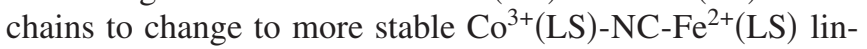
ear chains. This type of spin state transition is occurring around the $x=0.75$ sample for the present series. In this way, the structural disorder affects the spin states of the Co and Fe ions in these compounds. Similarly, because of the bridging nature of the $\mathrm{CN}$ ligand, PBA compounds may show linkage isomerism or cyanide flip. ${ }^{12,53}$ The extent of linkage isomerism depends mainly on the electronic structure of the metal ions and is related to the change in ligand field stabilization energies that results from the flipping of the $\mathrm{CN}$ ligand. ${ }^{53}$ As a result of this cyanide flipping during the sample preparation itself, few $\mathrm{Co}^{2+}(\mathrm{HS})-\mathrm{NC}-\mathrm{Fe}^{3+}(\mathrm{LS})$ and $\mathrm{Ni}^{2+}(\mathrm{HS})-\mathrm{NC}-\mathrm{Fe}^{3+}(\mathrm{LS})$ linear chains convert to $\mathrm{Co}^{2+}(\mathrm{LS})-\mathrm{CN}-\mathrm{Fe}^{3+}(\mathrm{HS})$ and $\mathrm{Ni}^{2+}(\mathrm{HS})-\mathrm{CN}-\mathrm{Fe}^{3+}(\mathrm{HS})$ linear chains, respectively, as the energy difference between these two configurations is quite less. This kind of structural disorder also changes the ligand field strength at the magnetic ions and thus causing the spin states of the magnetic ions to change. Therefore various kinds of structural disorders, that are present in the compounds of the series, change the ligand field strength at the magnetic ions and result in the different spin states of the $\mathrm{Co}, \mathrm{Ni}$, and $\mathrm{Fe}$ ions.

In the present study we have shown the variation of structural and magnetic properties of the compounds of $\left(\mathrm{Co}_{x} \mathrm{Ni}_{1-x}\right)_{1.5}\left[\mathrm{Fe}(\mathrm{CN})_{6}\right] \cdot z \mathrm{H}_{2} \mathrm{O}$ series by varying the composition $(x)$. As we increase the concentration of the Co ion in the parent compound $\mathrm{Ni}_{1.5}\left[\mathrm{Fe}(\mathrm{CN})_{6}\right] \cdot z \mathrm{H}_{2} \mathrm{O}$, the lattice parameter increases for the compositions up to $x=0.5$. However, for higher values of $x$, the lattice parameter shows a dip around the $x=0.75$ composition because of the increased amount of structural disorder in these compounds around $x$ $=0.75$. Similarly magnetic properties, e.g., $T_{C}, M_{\max }, H_{C}$, $M_{R}$, etc., deviate from the linear behavior around $x=0.75$, where the maximum amount of structural disorder is present. In this way, a structural disorder plays an important role in determining the structural and magnetic properties of these compounds. We can therefore control the structural and magnetic properties of these compounds by varying the composition provided structural defects are minimal. These structural defects arise during the sample preparation itself and therefore better preparation methods involving the controlled reaction of starting compounds $\left[\mathrm{Co}\left(\mathrm{NO}_{3}\right)_{2}, \mathrm{Ni}\left(\mathrm{NO}_{3}\right)_{2}\right.$, and $\mathrm{K}_{3} \mathrm{Fe}(\mathrm{CN})_{6}$ in our case] should be devised.

\section{SUMMARY AND CONCLUSIONS}

We have presented the structural and magnetic properties of the compounds of the $\left(\mathrm{Co}_{x} \mathrm{Ni}_{1-x}\right)_{1.5}\left[\mathrm{Fe}(\mathrm{CN})_{6}\right] \cdot z \mathrm{H}_{2} \mathrm{O}$ series. The compounds of the series have disordered fcc crystal structure as studied by the Mössbauer and IR techniques. The structural disorders appear as diffuse scattering in the neutron-diffraction patterns with a broad peaklike feature at the forbidden (100) position. The RMC simulations of the diffuse scattering reveal a correlated substitution of the water molecules, at the empty $\mathrm{Fe}(\mathrm{CN})_{6}$ sites, responsible for the observed broad peaklike feature at the (100) Bragg peak position. The $T_{C}$ for the compounds of the series decreases with increasing amount of the Co substitution and it is the lowest for the $x=0.75$ composition. A very weak magnetic scattering contribution to fundamental (nuclear) Bragg peaks (in the presence of a large modulated diffuse scattering) is observed in the neutron-diffraction patterns at $1.5 \mathrm{~K}$. An analysis of the high-temperature susceptibility data indicates ferrimagnetic correlations for the $x=1$ composition but a ferromagnetic correlation for all other compositions. Fielddependent magnetization studies reveal that all compounds (except $x=1$ ) of the series are ferromagnetic with positive exchange interactions between the nearest-neighbor low-spin $\mathrm{Co}^{2+}\left(S=\frac{1}{2}\right) / \mathrm{Ni}^{2+}(S=1)$ and mixed spin $\mathrm{Fe}^{3+}$ [low-spin $(S$ $\left.=\frac{1}{2}\right)$ and high-spin $\left.\left(S=\frac{5}{2}\right)\right]$ ions. However, the end compound $\mathrm{Co}_{1.5}\left[\mathrm{Fe}(\mathrm{CN})_{6}\right] \cdot z \mathrm{H}_{2} \mathrm{O}(x=1)$ of the series is a ferrimagnet with negative exchange interactions between the high-spin $\mathrm{Co}^{2+}\left(S=\frac{3}{2}\right)$ and the low-spin $\mathrm{Fe}^{3+}\left(S=\frac{1}{2}\right)$ and also between the low-spin $\mathrm{Co}^{2+}\left(S=\frac{1}{2}\right)$ and the high-spin $\mathrm{Fe}^{3+}\left(S=\frac{5}{2}\right)$ ions. All compounds of the series are hard magnets having an unusually high value of coercivity $(\sim 4 \mathrm{kOe})$. A possible correlation between magnetic irreversibility and magnetic hardness is evident from the $M_{\mathrm{FC}}$ and $M_{\mathrm{ZFC}}$ curves. The effects of varying structural disorder on the $T_{C}, M_{\max }, H_{C}, M_{R}$, etc., for the $\left(\mathrm{Co}_{x} \mathrm{Ni}_{1-x}\right)_{1.5}\left[\mathrm{Fe}(\mathrm{CN})_{6}\right] \cdot z \mathrm{H}_{2} \mathrm{O}$ series are evident as the large deviations in their values are observed around the $x$ $=0.75$ composition where the largest amount of structural disorder is present. The present study therefore highlights the importance of structural disorders in designing molecular magnets with varying magnetic properties.

\section{ACKNOWLEDGMENTS}

A.K. and S.M.Y. are grateful to S. L. Chaplot, S. K. Kulshreshtha, and V. C. Sahni for their encouragement and support in this work. A.K. is thankful to R. Chitra for her help in recording the $\mathrm{X}$-ray-diffraction patterns.

\footnotetext{
*Corresponding author. Fax: +91 22 25505151. Email address: smyusuf@barc.gov.in

${ }^{1}$ S. I. Ohkoshi, Y. Abe, A. Fujishima, and K. Hashimoto, Phys. Rev. Lett. 82, 1285 (1999).
}

${ }^{2}$ E. Coronado, M. C. Giménez-López, G. Levchenko, F. M. Romero, V. García-Baonza, A. Milner, and M. Paz-Pasternak, J. Am. Chem. Soc. 127, 4580 (2005).

${ }^{3}$ H. L. Sun, H. Shi, F. Zhao, L. Qi, and S. Gao, Chem. Commun. 
(Cambridge) 34, 4339 (2005).

${ }^{4}$ O. Sato, T. Kawakami, M. Kimura, S. Hishiya, S. Kubo, and Y. Einaga, J. Am. Chem. Soc. 126, 13176 (2004).

${ }^{5}$ A. Widmann, H. Kahlert, I. Petrovic-Prelevic, H. Wulff, J. V. Yakhmi, N. Bagkar, and F. Scholz, Inorg. Chem. 41, 5706 (2002).

${ }^{6}$ H. Miyasaka, H. Takahashi, T. Madanbashi, K. Sugiura, R. Clérac, and H. Nojiri, Inorg. Chem. 44, 5969 (2005).

${ }^{7}$ P. Franz, C. Ambrus, A. Hauser, D. Chernyshov, M. Hostettler, J. Hauser, L. Keller, K. Krämer, H. Stoeckli-Evans, P. Pattison, H.-Beat Bürgi, and S. Decurtins, J. Am. Chem. Soc. 126, 16472 (2004).

${ }^{8}$ W. Dong, Li-Na Zhu, Hai-Bin Song, Dai-Zheng Liao, Zong-Hui Jiang, Shi-Ping Yan, P. Cheng, and S. Gao, Inorg. Chem. 43, 2465 (2004).

${ }^{9}$ S. Ohkoshi, Ken-Ichi Arai, Y. Sato, and K. Hashimoto, Nat. Mater. 3, 857 (2004).

${ }^{10}$ Z. Lu, X. Wang, Z. Liu, F. Liao, S. Gao, R. Xiong, H. Ma, D. Zhang, and D. Zhu, Inorg. Chem. 45, 999 (2006).

${ }^{11}$ A. Kumar, S. M. Yusuf, and L. Keller, Phys. Rev. B 71, 054414 (2005).

${ }^{12}$ A. Kumar and S. M. Yusuf, Physica B 362, 278 (2005).

${ }^{13}$ J. V. Yakhmi, Physica B 321, 204 (2002).

${ }^{14}$ S. Choudhury, G. K. Dey, and J. V. Yakhmi, J. Cryst. Growth 258, 197 (2003).

${ }^{15}$ N. Bagkar, A. Widmann, H. Kahlert, G. Ravikumar, S. M. Yusuf, F. Scholz, and J. V. Yakhmi, Philos. Mag. 85, 3659 (2005).

${ }^{16}$ N. Bagkar, S. Choudhury, K.-H. Kim, P. Chowdhury, S.-I. Lee, and J. V. Yakhmi, Thin Solid Films 513, 325 (2006).

${ }^{17}$ O. Sato, T. Iyoda, A. Fujishima, and K. Hashimoto, Science 272, 704 (1996).

${ }^{18}$ O. Sato, V. Einag, T. Iyoda, A. Fujishim, and K. Hashimoto, J. Electrochem. Soc. 144, 11 (1997).

${ }^{19}$ S. Juszczyk, C. Johansson, M. Hanson, A. Ratuszna, and G. Małecki, J. Phys.: Condens. Matter 6, 5697 (1994).

${ }^{20}$ Y. Einaga, S. Ohkoshi, O. Sato, A. Fujishima, and K. Hashimoto, Chem. Lett. 27, 585 (1998).

${ }^{21}$ A. Kumar, S. M. Yusuf, and L. Keller, Physica B 385-386, 444 (2006).

${ }^{22}$ H. J. Buser, D. Schwarzenbach, W. Petter, and A. Ludi, Inorg. Chem. 16, 2704 (1977).

${ }^{23}$ F. Herren, P. Fischer, A. Lüdi, and W. Hälg, Inorg. Chem. 19, 956 (1980).

${ }^{24}$ S. Yamada, K. Kuwabara, and K. Kuomoto, Mater. Sci. Eng., B 49, 89 (1997).

${ }^{25}$ J. Rodriguez-Carvajal, FULLPROF, April 2005, LLB CEA-CNRS.

${ }^{26}$ C. W. Ng, J. Ding, Y. Shi, and L. M. Gan, J. Phys. Chem. Solids 62, 767 (2001).

${ }^{27}$ C. W. Ng, J. Ding, and L. M. Gan, J. Solid State Chem. 156, 400 (2001)

${ }^{28}$ M. Kamiya, M. Hanawa, Y. Moritomo, Y. Isobe, J. Tateishi, K. Kato, and A. Nakamura, Phys. Rev. B 69, 052102 (2004).

${ }^{29}$ S. Juszczyk, A. Ratuszna, K. Kaczmarska, G. Matecki, M. Han- son, and C. Johansson, J. Magn. Magn. Mater. 157/158, 499 (1996).

${ }^{30}$ W. R. Entley and G. S. Girolami, Inorg. Chem. 33, 5165 (1994).

${ }^{31}$ Infrared and Raman Spectra of Inorganic and Coordination Compounds. Part B: Applications in Coordination, Organometallic and Bioorganic Chemistry, edited by K. Nakamoto, 5th ed. (Wiley Interscience, New York, 1997).

${ }^{32}$ A. Gómez, V. H. Lara, P. Bosch, and E. Reguera, Powder Diffr. 17, 144 (2002).

${ }^{33}$ A. Mellergård, RMCPOW: Version 2.1, 2004-02-06, website: ftp::/ftp.studsvik.uu.se/Pub/RMCPOW

${ }^{34}$ S. I. Ohkoshi and K. Hashimoto, Phys. Rev. B 60, 12820 (1999).

${ }^{35}$ J. S. Smart, Am. J. Phys. 23, 356 (1955).

${ }^{36}$ T. Wasiutyński, Z. Szeglowski, A. W. Pacyna, and M. Bałanda, Physica B 253, 305 (1998).

${ }^{37}$ M. Verdaguer, A. Bleuzen, V. Marvaud, J. Vaissermann, M. Seuleiman, C. Desplanches, A. Scuiller, C. Train, R. Garde, G. Gelly, C. Lomenech, I. Rosenman, P. Veillet, C. Cartier, and F. Villain, Coord. Chem. Rev. 190-192, 1023 (1999).

${ }^{38}$ C. Y. Huang, J. Magn. Magn. Mater. 51, 1 (1985).

${ }^{39}$ S. M. Yusuf, L. Madhav Rao, P. L. Paulose, and V. Nagarajan, J. Magn. Magn. Mater. 166, 349 (1997).

${ }^{40}$ G. G. Kenning, D. Chu, and R. Orbach, Phys. Rev. Lett. 66, 2923 (1991).

${ }^{41}$ R. V. Chamberlin, M. Hardiman, L. A. Turkevich, and R. Orbach, Phys. Rev. B 25, 6720 (1982).

${ }^{42}$ H. A. Katori and A. Ito, J. Phys. Soc. Jpn. 63, 3122 (1994).

${ }^{43}$ S. M. Yusuf, M. Sahana, K. Dörr, U. K. Ro $\beta$ ler, and K.-H. Müller, Phys. Rev. B 66, 064414 (2002).

${ }^{44}$ R. S. Freitas, L. Ghivelder, F. Damay, F. Dias, and L. F. Cohen, Phys. Rev. B 64, 144404 (2001).

${ }^{45}$ B. J. Hickey, M. A. Howson, S. O. Musa, G. J. Tomaka, B. D. Rainford, and N. Wiser, J. Magn. Magn. Mater. 147, 253 (1995).

${ }^{46}$ J. C. Denardin, A. L. Brandl, M. Knobel, P. Panissod, A. B. Pakhomov, H. Liu, and X. X. Zhang, Phys. Rev. B 65, 064422 (2002).

${ }^{47}$ M. D. Mukadam, S. M. Yusuf, P. Sharma, and S. K. Kulshreshtha, J. Magn. Magn. Mater. 269, 317 (2004).

${ }^{48}$ S. M. Yusuf and L. Madhav Rao, J. Phys.: Condens. Matter 7, 5891 (1995).

${ }^{49}$ S. M. Yusuf, V. C. Sahni, and L. Madhav Rao, J. Phys.: Condens. Matter 7, 873 (1995).

${ }^{50}$ T. V. Chandrasekhar Rao, P. Raj, S. M. Yusuf, L. Madhav Rao, A. Sathyamoorthy, and V. C. Sahni, Philos. Mag. B 74, 279 (1996).

${ }^{51}$ S. M. Yusuf, L. Madhav Rao, R. Mukhopadhyay, S. Giri, K. Ghoshray, and A. Ghoshray, Solid State Commun. 101, 145 (1997).

${ }^{52}$ V. Ksenofontov, G. Levchenko, S. Reiman, P. Gütlich, A. Bleuzen, V. Escax, and M. Verdaguer, Phys. Rev. B 68, 024415 (2003).

${ }^{53}$ V. Gadet, T. Mallah, I. Castro, and M. Verdaguer, J. Am. Chem. Soc. 114, 9213 (1992). 